\section{Japan justifies whaling stance}

As Japan's commissioner to the International Whaling Commission (IWC), I disagree that the IWC's review process of scientific whaling is "a waste of time" (A. Brierley and P. Clapham Nature 529, 283; 2016).

The process comprises an independent expert-panel review and a wider review by the IWC Scientific Committee. Research proponents have no say in the expert panel's conclusions. Japan has given due regard to the IWC's criticisms after peer review of its NEWREP-A proposal, which gave the scientific rationale for lethal sampling (see go.nature.com/ wqpxyb; go.nature.com/vxjaz6).

Brierley and Clapham say that Japan failed to alter its research plans "in any meaningful way" following recommendations by the IWC Scientific Committee that it should explore widely used non-lethal alternatives. In fact, those methods were included in the research plans for evaluation in light of the research objectives. As the International Court of Justice recognized in 2014, certain data cannot be obtained by nonlethal methods (see go.nature. com/fboxrt). Japan's new research programme includes both lethal and non-lethal research methods.

The authors' allegation that Japan's whaling is "ostensibly" for research is no basis for proper scientific debate. Japan has made clear that it is always willing to answer questions on its research programme (see go.nature.com/ dut $2 \mathrm{kx}$ ), and looks forward to constructive scientific discussion at the committee's June meeting. Joji Morishita National Research Institute of Far Seas Fisheries, Shizuoka, Japan. jmorishita@affrc.go.jp

\section{NIH push to stop sexual harassment}

As the leading US government funder of scientific research, we at the National Institutes of Health
(NIH) are deeply concerned about sexual harassment in science (Nature 529, 255; 2016). With the help of colleagues in government, academia and the private sector, the NIH aims to identify the steps necessary to end this in all NIH-supported research workplaces and scientific meetings.

In September last year, we restated our expectation that organizers of NIH-supported conferences and meetings should assure a safe environment, free of discrimination (see go.nature.com/zmukk8).

Over the next few weeks to months, we plan to work with governmental, academic and private-sector colleagues to identify potential steps to translating our expectations into reality. An important first step will be to gather as much data as possible to more fully understand the nature and extent of sexual harassment among scientists. These data should guide us in determining what kinds of policy and procedure are most likely to help. We will also work to determine what levers are already available to influential stakeholders - us as funders, as well as university administrators and departments, journal editors, and organizers and hosts of scientific meetings.

We owe this to our colleagues and the public, who trust in our ability to make the biomedical research enterprise the best that it can be.

Michael Lauer, Hannah Valantine, Francis S. Collins National Institutes of Health, Bethesda, Maryland, USA. michael.lauer@nih.gov

\section{Australians rush to reject primate bill}

A bill introduced in the Australian Senate proposes an amendment that would prohibit imports of live non-human primates for research purposes (see Nature http://doi.org/bcqx; 2016). We call for the Senate to reject this bill in support of ethically conducted research and preserving the animals' longterm health, for which exchange between international breeding facilities is crucial.

The bill was referred for enquiry to the Senate Legislation Committee for Environment and Communications, which sought public submissions in late 2015 (see go.nature.com/mjahre). Three days before the first public hearing on 5 February, only 2 out of 56 submissions argued against the amendment.

At that point, we contacted the Australian scientific community - heads of research institutes and those working with non-human primates - and discovered that they were largely unaware of the proposed legislation.

A flurry of written submissions and last-minute personal representations to members of the Senate followed, all calling for rejection of the bill. The international community took up the issue, with many scientific societies and research institutes reacting within 48 hours (see go.nature.com/oihuxp).

The Senate committee accepted many submissions after the closing date and is due to submit its report early this month. The episode demonstrates the alacrity with which scientists, typically a reticent group, are prepared to engage with the political process when the issue is perceived as important for the advancement of science.

Nicholas Price, James Bourne, Marcello Rosa Monash University, Melbourne, Australia. nicholas.price@monash.edu

\section{Transparency: issues are not that simple}

We find Stephan Lewandowsky and Dorothy Bishop's framing of science governance to be overly simplistic and in need of a firmer evidence base ('Don't let transparency damage science' Nature 529, 459-461; 2016).

The authors' analysis is biased by its reliance on testimonials from the narrow range of invited experts at last year's Royal Society meeting (see go.nature.com/ zptirs). Complex issues associated with openness and transparency also need to be taken into account (see S. Jasanoff Law Contemp. Probl. 69, 21-45; 2006).

The authors present important topics such as expertise, disciplinary boundaries and communication as simple dichotomies. These divisions overlook extensive nuanced evidence from the social-science literature about who counts as an expert and under which conditions (see, for example, go.nature.com/xdfzrn).

In our view, governance issues around openness and transparency should not be framed only by the research community. The debate must also include representatives from across the broad range of public viewpoints.

Warren Pearce, Sarah Hartley, Brigitte Nerlich University of Nottingham, UK.

warren.pearce@nottingham.ac.uk

\section{Transparency: an opaque illustration}

We question the choice of the padlock and dagger illustration you used to open the discussion by Stephan Lewandowsky and Dorothy Bishop ('Don't let transparency damage science' Nature 529, 459-461; 2016). To us, this falsely implies that the article is about open access to journal publications and, by its association with the title, that open-access publishing presents a threat to science.

The authors send no such scary message, which calls attention to the more general concepts of openness and transparency in providing access to original research data.

Karen Shashok Granada, Spain. Remedios Melero CSIC Institute of Agrochemistry and Food Technology (IATA), Valencia, Spain. kshashok@kshashok.com 